\title{
ADVANCED AMPLITUDE CENTERING AS AN INVIGORATING MANIPULATION FOR UNIFIED WAVELENGTH SPECTRAL RESOLUTION OF TERNARY MIXTURES
}

\author{
HAYAM M. LOTFYa, SARAH S. SALEH ${ }^{*}$ \\ aAnalytical Chemistry Department, Faculty of Pharmacy, Cairo University, Kasr-El Aini, 11562 Cairo, Egypt, bAnalytical Chemistry \\ Department, Faculty of Pharmacy, October University for Modern Sciences and Arts (MSA), $117876^{\text {th }}$ October, Egypt \\ Email: drsarahsalah@gmail.com
}

Received: 06 Jan 2017 Revised and Accepted: 09 Mar 2017

\section{ABSTRACT}

Objective: This work presented the novel spectrophotometric approach namely, advanced amplitude centering (AAC). The method was applied for the resolution of ternary mixtures with partially or completely overlapped spectra.

Methods: Advanced amplitude centering was based on the determination of ternary mixtures using single divisor where the concentrations of the components are determined through progressive manipulation performed on the same ratio spectrum. The centered amplitude at unified wavelength was resolved and applied for the determination of three components with partially and severely overlapped spectra. The work discussed the applications and advantages of the novel univariate advanced amplitude centering compared to the chemometric model, partial least square (PLS).

Results: The specificity of the proposed methods was checked using laboratory-prepared mixtures of amlodipine (AML), valsartan (VAL) and hydrochlorothiazide (HCT) and was successfully applied for the analysis of two pharmaceutical formulations. The validity of results was assessed by applying the standard addition technique.

Conclusion: The results obtained were found to agree statistically with those obtained by a reported method, showing no significant difference with respect to accuracy and precision.

Keywords: Amplitude centering, Severely overlapping spectra, Amlodipine, Valsartan, Hydrochlorothiazide, Resolution of mixtures

(C) 2017 The Authors. Published by Innovare Academic Sciences Pvt Ltd. This is an open access article under the CC BY license (http://creativecommons.org/licenses/by/4.0/) DOI: http://dx.doi.org/10.22159/ijpps.2017v9i5.16960

\section{INTRODUCTION}

Analysis of complex mixtures containing three or more components represented a challenge for analysts. For resolving such mixtures, Analysts preferred using hyphenated instrumentations such as LCMS, GC-MS, LC-NMR [1, 2] , which consume lots of time and money. Unfortunately, the spectrophotometric methods, which provided a solution for complex ternary mixtures, were tedious, require several manipulating steps and exhibited several limitations [3-5]. Although chemometric models are cheap, but they require special software and a large number of synthetic mixtures $[6,7]$.

The components of interest were amlodipine (AML), valsartan (VAL) and hydrochlorothiazide (HCT). Several analytical techniques, including chromatography, spectrophotometry and electrochemistry, were reported for the analysis of each the components individually: AML [8-12] , VAL [13-16] and HCT [17-19] The binary mixture of AML and VAL was determined using spectrophotometric [20] and HPLC methods [21] while the mixture containing AML and HCT was determined using spectrophotometric method [22] and capillary electrophoresis [23] The binary mixture of VAL and HCT was determined using spectroscopic, TLC and HPLC methods [24].

The determination of the ternary mixture of AML, VAL and HCT was reported using spectrophotometric methods which utilised multistep manipulation using several equations and wavelengths [25] but with certain limitations as the existence of iso-absorptive point [26] Advanced chemometric tools were also reported [27, 28] which required certain decoding. TLC and HPLC chromatographic methods were reported for the analysis too [29].

The concept of amplitude centering was firstly introduced as a progressive determination of three components in their ternary mixture where their spectra were partially overlapped [30] This was done through the same ratio spectrum via their corresponding amplitudes using single divisor.
The aim of the presented work was to introduce a modification on amplitude centering method which allows the simultaneous determination of any ternary mixture either with partially or completely overlapping spectra using single divisor by unified wavelength spectral resolution. The resolution efficiency of the proposed technique was checked by the analysis of the ternary mixtures' spectra AML, VAL and HCT and their pharmaceutical formulations.

Unlike all the reported methods, the advanced amplitude centering (AAC) was selective, less expensive, time-saving and could be applied for the analysis of any ternary mixture with no limitations or sophisticated instrument. Additionally, this procedure had comparable precision and accuracy to the PLS chemometric ones but with more simplicity, as there is no need for special software $\left(\right.$ Matlab $^{\circledR}$ ) and this advantage permits its wider application in solving analytical problems.

\section{Theory of advanced amplitude centering (AAC)}

This novel approach of advanced amplitude centering (AAC) which was introduced by Saleh et al. [30] The approach depended on the progressive determination of three components in their ternary mixture through the same ratio spectrum via their corresponding amplitudes using single divisor. It could be applied for a ternary mixture of $\mathrm{X}, \mathrm{Y}$ and $\mathrm{Z}$ with partially or completely overlapped spectra. This novel approach was based on amplitude difference, which is the first step of the constant center spectrophotometric method [31] in order to resolve the centered amplitude recorded at a single wavelength on the ratio spectrum of the mixture to amplitudes corresponding to each component in the ternary mixture.

\section{Approach for partially overlapping spectra}

For a mixture of three drugs $(X+Y+Z)$, at $\lambda_{1}$ and $\lambda_{2}: X$ and $Y$ spectra show overlapping where $Z$ is extended. This method consisted of 
three steps complementary to each other namely; amplitude calculation and amplitude factor then finally amplitude subtraction.

By dividing the spectrum of the mixture by a known concentration of $\mathrm{Z}$ as a divisor ( $\left.\mathrm{Z}^{\prime}\right)$. The division will give a new spectrum that can be summarized as follows:

$$
\frac{X+Y+Z}{Z^{\prime}}=\frac{X}{Z^{\prime}}+\frac{Y}{Z^{\prime}}+\frac{Z}{Z^{\prime}}=\frac{X}{Z^{\prime}}+\frac{Y}{Z^{\prime}}+\text { Constant }
$$

The amplitude calculation step for component $\mathrm{Z}$ where the amplitude $\mathrm{Z} / \mathrm{Z}$ constant can be accurately determined at the extended region parallel to the wavelength axis,

Then subtract this constant value $\mathrm{Z} / \mathrm{Z}$ ' to get the ratio spectrum of $\mathrm{X}$ and $\mathrm{Y}$

$$
=\left[\frac{X}{Z^{\prime}}+\frac{Y}{Z^{\prime}}+\frac{Z}{Z^{\prime}}\right]-\frac{Z}{Z^{\prime}}=\frac{X}{Z^{\prime}}+\frac{Y}{Z^{\prime}}
$$

The obtained ratio spectrum of a binary mixture of $X$ and $Y$ $\left(\frac{X}{Z^{\prime}}+\frac{Y}{Z^{\prime}}\right)$ which exhibit complete overlapped ratio spectra at two wavelengths $\lambda_{1}$ and $\lambda_{2}$.

$$
\begin{aligned}
& \mathrm{P}_{1}=\mathrm{P}_{\mathrm{X} 1}+\mathrm{P}_{\mathrm{Y} 1} \text { at } \lambda_{1} \\
& \mathrm{P}_{2}=\mathrm{P}_{\mathrm{X} 2}+\mathrm{P}_{\mathrm{Y} 2} \text { at } \lambda_{2}
\end{aligned}
$$

Where $\mathrm{P}_{1}$ and $\mathrm{P}_{2}$ is the amplitudes of the ratio spectrum of the mixture at $\lambda_{1}$ and $\lambda_{2}$ and $\mathrm{Px}_{1}, \mathrm{Px}_{1}$ and $\mathrm{P}_{\mathrm{Y} 1}, \mathrm{P}_{\mathrm{Y} 1}$ are the corresponding amplitudes of $\mathrm{X}$ and $\mathrm{Y}$ at the two chosen wavelengths.

The amplitude factor is calculated in order to cancel the effect of $Y$ at the two selected wavelengths, the equality factor of pure $\mathrm{Y}\left(\mathrm{F}_{\mathrm{Y}}\right)$ is calculated which is the amplitude ratio of the different concentration of pure $Y$ at $\lambda_{1}$ and $\lambda_{2}$ is calculated:

$$
F_{Y}=P_{Y 1} / P_{Y} 2 . P_{Y 1}=F_{Y} P_{Y} 2
$$

Then substitute $\mathrm{P}_{\mathrm{Y} 1}$ at equation (3) as follows:

$$
\mathrm{P}_{1}=\mathrm{P}_{\mathrm{X} 1}+\mathrm{F}_{\mathrm{Y}} \mathrm{P}_{\mathrm{Y} 2}
$$

By multiply equation (4) by $\mathrm{F}_{\mathrm{Y}}$

$$
\mathrm{F}_{\mathrm{Y}} \mathrm{P}_{2}=\mathrm{F}_{\mathrm{Y}} \mathrm{P}_{\mathrm{X} 2}+\mathrm{F}_{\mathrm{Y}} \mathrm{P}_{\mathrm{Y} 2}
$$

The difference between the two equation (5) and (6), FY AY2 will be cancelled as follows:

$$
\Delta \mathrm{P}\left(\mathrm{P}_{1}-\mathrm{F}_{\mathrm{Y}} \mathrm{P}_{2}\right)=\mathrm{P}_{\mathrm{X} 1}-\mathrm{F}_{\mathrm{Y}} \mathrm{P}_{\mathrm{X} 2}
$$

Therefore, $\Delta P\left(P_{1}-F_{Y} P_{2}\right)$ of the mixture is dependent only on the values of $C_{X}$, and is independent of the value of $C_{Y}$ in the mixture.

The amplitude calculation step for $\mathrm{X}$ in the mixture starts with amplitude difference method where a regression equation was computed representing the linear relationship between the difference of ratio amplitudes $(\Delta \mathrm{P})\left(\mathrm{P}_{\mathrm{x} 1}-\mathrm{F}_{\mathrm{Y}} \mathrm{P}_{\mathrm{X} 2}\right)$ of different concentration of pure $X$ at $\lambda_{1}$ and $\lambda_{2}$ using a the previously used concentration of $\mathrm{Z}^{\prime}$ as a divisor versus the corresponding ratio amplitude $\mathrm{P}_{\mathrm{x} 1}$ at $\lambda_{1}$; therefore

$$
\left(\mathrm{P}_{\mathrm{X} 1}-\mathrm{F}_{\mathrm{Y}} \mathrm{P}_{\mathrm{X} 2}\right)=\text { slope } \mathrm{P}_{\mathrm{X} 1} \pm \text { intercept } .
$$

The postulated amplitude value related to component $\mathrm{X}$ only at $\lambda_{1}\left(\mathrm{P}_{(\mathrm{x}) \text { postulated }}\right)$ in the mixture of $(\mathrm{X}+\mathrm{Y})$ represents $\mathrm{P}_{\mathrm{x} 1}$ or $\left(\mathrm{X} / \mathrm{Z}^{\prime}\right) 1$ can be calculated via the previously computed regression equation (8) using $\Delta \mathrm{P}\left(\mathrm{P}_{1}-\mathrm{F}_{\mathrm{Y}} \mathrm{P}_{2}\right)$ of the mixture at the two selected wavelengths where $\left(F_{Y}\right)$ is the equality factor of pure $Y$ at these wavelengths.

Finally, the amplitude subtraction step was applied where the amplitude $\left(y / z^{\prime}\right)$ corresponding to $Y$ can be calculated by subtracting the recorded amplitude of the ratio spectrum of the resolved binary mixture $(X+Y) \quad(P$ recorded $)$ at $\left(\lambda_{1}\right)$, and postulated amplitude corresponding to component $\mathrm{X}$ only $\left(\mathrm{P}_{(\mathrm{X}) \text { postulated }}\right)$ in the mixture at the same wavelength $\left(\lambda_{1}\right)$.

$$
\frac{Y}{Z^{\prime}}=\left(\frac{X}{Z^{\prime}}+\frac{Y}{Z^{\prime}}\right) 1-\left(\frac{X}{Z^{\prime}}\right) 1
$$

The concentration of $\mathrm{X}$ or $\mathrm{Y}$ or $\mathrm{Z}$ is calculated using the regression equation representing the correlation between the amplitudes of ratio spectra $\frac{X}{Z^{\prime}}$ or $\frac{Y}{Z^{\prime}}$ or $\frac{Z}{Z^{\prime}}$ at $\lambda_{1}$ and the corresponding concentration of pure $\mathrm{X}$ or $\mathrm{Y}$ or $\mathrm{Z}$.

\section{Approach For completely overlapping spectra}

This Amplitude centering consisted of two steps complementary to each other namely; amplitude calculation and amplitude subtraction. For a mixture of three drugs $(\mathrm{X}+\mathrm{Y}+\mathrm{Z})$ with no extension of $\mathrm{Z}$. The ratio spectra of the mixture is obtained by dividing the spectrum of the mixture by a known concentration of $\mathrm{Z}$ as a divisor ( $\left.\mathrm{Z}^{\prime}\right)$. The division will give a new spectrum that can be summarized previously in equation (1).

Amplitude calculation step starts with amplitude difference method which was applied twice on the ratio spectra of different concentrations of pure $\mathrm{Y}$ and $\mathrm{X}$ using $\mathrm{Z}^{\prime}$ as a divisor separately at $\lambda_{1}$ and $\lambda_{2}$, where $X$ shows two equal amplitudes at these chosen two wavelengths and at $\lambda_{1}$ and $\lambda_{3}$ where $Y$ shows two equal amplitudes at these chosen two wavelengths, so the difference will represent component $\mathrm{Y}$ only or $\mathrm{X}$ only. Two regression equations were computed representing the linear relationships between the difference of amplitudes $(\Delta \mathrm{P}=\{P 1-P 2\})$ of different concentrations of pure $\mathrm{Y}$ at $\lambda_{1}$ and $\lambda_{2}$ or $(\Delta \mathrm{P}=\{P 1-P 3\})$ of different concentrations of pure $\mathrm{X}$ at $\lambda_{1}$ and $\lambda_{3}$ versus the corresponding ratio amplitude of $\mathrm{Y}$ or $\mathrm{X}$ at $\lambda_{1}$ this can be summarized as follows:

$$
\begin{gathered}
\{P 1-P 2\}=\text { slope }\left(\frac{Y}{Z^{\prime}}\right) 1^{ \pm \text {intercept } \ldots \ldots . . .}(10) \\
\{P 1-P 3\}=\text { slope }\left(\frac{X}{Z^{\prime}}\right) 1^{ \pm \text {intercept } \ldots \ldots \ldots . . .}
\end{gathered}
$$

Where, $\{P 1-P 2\}$ represent $\left(\frac{Y}{Z^{\prime}}\right) 1$ and $\left(\frac{Y}{Z^{\prime}}\right) 2^{\text {or }}\{P 1-P 3\}$ represent $\left(\frac{X}{Z^{\prime}}\right) 1$ and $\left(\frac{X}{Z^{\prime}}\right) 2^{\text {is the amplitude difference at } \lambda_{1} \text { and } \lambda_{2}}$ or $\lambda_{1}$ and $\lambda_{3}$ and $\left(\frac{Y}{Z^{\prime}}\right) 1$ or $\left(\frac{X}{Z^{\prime}}\right) 1$ corresponding to component $\mathrm{Y}$ or $\mathrm{X}$ at $\lambda_{1}$.

The postulated amplitude value which corresponding to component $\mathrm{Y}$ or $\mathrm{X}$ in the mixture $\left(\mathrm{P}_{(\mathrm{Y}) \text { postulated }}\right)$ or $\left(\mathrm{P}_{(\mathrm{x})}\right.$ postulated $)$ was obtained by substitution in previously computed regression equations using amplitude difference between two wavelengths $\left(\lambda_{1}\right.$ and $\left.\lambda_{2}\right)$ in case of Y Eq (10) or $\left(\lambda_{1}\right.$ and $\left.\lambda_{3}\right)$ in case of X Eq (11), where the constant Z/Z' will be cancelled along with those corresponding to $\mathrm{X}$ or $\mathrm{Y}$ respectively which show two equal amplitudes at these chosen two wavelengths.

Finally, apply amplitude subtraction where the amplitude corresponding to the constant $\mathrm{Z} / \mathrm{Z}^{\prime}$ can be calculated by subtracting the recorded amplitude of the mixture $(\mathrm{P}$ recorded $)$ at $\left(\lambda_{1}\right)$, and the previously calculated postulated amplitude $\left(\mathrm{P}_{\text {postulated }}\right)$ corresponding to component $\mathrm{Y}$ and $\mathrm{X}$ in the mixture separately at $\lambda_{1}$.

$$
\begin{aligned}
& \mathrm{P}_{\mathrm{Z}}=\left(\mathrm{P}_{\text {recorded }}\right)-\left(\mathrm{P}_{\text {postulated of } \mathrm{X} \text { and } \mathrm{Y}}\right) \\
& \frac{Z}{Z^{\prime}}=\left[\frac{X}{Z^{\prime}}+\frac{Y}{Z^{\prime}}+\frac{Z}{Z^{\prime}}\right]-\left[\frac{X}{Z^{\prime}}+\frac{Y}{Z^{\prime}}\right]
\end{aligned}
$$

The concentration of $\mathrm{X}$ or $\mathrm{Y}$ or $\mathrm{Z}$ is calculated using the regression equations representing the correlation between the amplitudes of ratio spectra $\frac{X}{Z^{\prime}}$ or $\frac{Y}{Z^{\prime}}$ or $\frac{Z}{Z^{\prime}}$ at the same wavelength $\lambda_{1}$ and the corresponding concentration of $\mathrm{X}$ or $\mathrm{Y}$ or $\mathrm{Z}$. 


\section{MATERIALS AND METHODS}

\section{Apparatus and software}

Shimadzu-UV 1800 double beam UV-Visible spectrophotometer (Japan) with matched $1 \mathrm{~cm}$ quartz cells at 200-800 $\mathrm{nm}$ range were used for all absorbance measurements. Spectra were automatically obtained by Shimadzu UV-Probe 2.32 system software.

\section{Chemicals and reagents}

\section{Pure samples}

|Amlodipine (AML), valsartan (VAL) and hydrochlorothiazide (HCT) were supplied by Sigma-Aldrich (USA). Their purity was found to be $99.04 \pm 0.65,99.32 \pm 0.91$ and $100.11 \pm 0.91$ for AML, VAL and HCT by the official methods [32] respectively.

\section{Market sample}

Exforge HCT® film coated tablets. Formulation (A) labeled to contain $10 \mathrm{mg}$ of AML, $160 \mathrm{mg}$ of VAL and $25 \mathrm{mg}$ of HCT per tablet (batch number: S0092). Formulation (B) labeled to contain $5 \mathrm{mg}$ of AML, $160 \mathrm{mg}$ of VAL and $12.5 \mathrm{mg}$ of HCT per tablet (batch number: S0250). Both formulations were manufactured by Novartis pharmaceutical cooperation, USA.

\section{Solvents}

Analytical grade methanol (SD fine-chem limited-Mumbai) and distilled water.

\section{Standard solutions}

\section{Stock solutions}

AML, VAL and HCT were prepared in a solvent mixture of methanol: water $(50: 50 \mathrm{v} / \mathrm{v})$, of concentration $1 \mathrm{mg} / \mathrm{ml}$. This solvent mixture ratio completely dissolved the three drugs quantities with the least amount of methanol to economize the usage of organic solvent, which is cost effective and eco-friendly.

\section{Working solutions}

They were freshly prepared by dilution from the stock solutions with the solvent mixture to obtain a concentration $40 \mu \mathrm{g} / \mathrm{ml}$ for AML and VAL; and $20 \mu \mathrm{g} / \mathrm{ml}$ for HCT.

\section{Procedure}

\section{Linearity and construction of calibration curves}

Aliquots equivalent to $(4-36 \mu \mathrm{g} / \mathrm{ml}),(2-42 \mu \mathrm{g} / \mathrm{ml})$ and $(2-20 \mu \mathrm{g} / \mathrm{ml})$ of AML, VAL and HCT were prepared separately in a solvent mixture of methanol: water $(50: 50 \mathrm{v} / \mathrm{v})$. The absorption spectra of the prepared solutions were measured at $(200-400 \mathrm{~nm})$ and stored in the computer.

\section{Advanced Amplitude centering (AAC)}

The stored zero order absorption spectra of the three drugs were divided by the spectrum of $24 \mu \mathrm{g} / \mathrm{ml}$ of AML.

\section{For partially overlapped spectra}

The peak amplitudes of the obtained ratio spectra at 239.5 and $275.5 \mathrm{~nm}$ were recorded. Equality factor (F) was calculated for VAL ratio spectra at 239.5 and $275.5 \mathrm{~nm}\left(\mathrm{P}_{275.5} / \mathrm{P}_{239.5}\right)$. The amplitudes of HCT at $239.5 \mathrm{~nm}$ of the stored spectra were multiplied by the equality factor $(\mathrm{F})$ of pure VAL. The amplitude difference $(\Delta \mathrm{P})$ of the ratio spectra of HCT at $275.5 \mathrm{~nm}$ and $239.5 \mathrm{~nm}$, after multiplying the later by $\mathrm{F}$, was calculated.

A linear regression was constructed between this amplitude difference $(\Delta \mathrm{P}$ 275.5-239.5) of HCT against its corresponding amplitude at $275.5 \mathrm{~nm}$ and the regression equation was computed. Two calibration curves were constructed between the amplitudes at 275.5 $\mathrm{nm}$ against the corresponding concentration of both HCT and VAL and the regression equations were computed. A calibration curve was constructed between the constant amplitudes at plateau region (350$380 \mathrm{~nm}$ ) against the corresponding concentration of AML and the regression equation was computed.

\section{For completely overlapped spectra}

The amplitude difference $(\Delta \mathrm{P})$ of the ratio spectra of HCT at 275.5 $\mathrm{nm}$ and $289.5 \mathrm{~nm}$ was calculated and linear regression was constructed between this amplitude differences $(\Delta \mathrm{P}$ 275.5-289.5) of HCT against its corresponding amplitude at $289.5 \mathrm{~nm}$ where the regression equation was computed. Meanwhile, the amplitude difference $(\Delta \mathrm{P})$ of the ratio spectra of VAL at $289.5 \mathrm{~nm}$ and $264.5 \mathrm{~nm}$ was calculated and linear regression was constructed between this amplitude differences $\left(\Delta \mathrm{P}_{289.5-264.5}\right)$ of VAL against its corresponding amplitude at $289.5 \mathrm{~nm}$ where the regression equation was computed. Calibration curves were constructed between the amplitudes at $289.5 \mathrm{~nm}$ against the corresponding concentration of each of AML, VAL and HCT and the regression equations were computed.

\section{Construction of calibration set for PLS model}

Multilevel fractional factorial design $[33,34]$ was used for the construction of the calibration and validation sets. A five-level, fivefactor calibration design was used. Fifteen mixtures were used for constructing the calibration set. The laboratory prepared mixtures of each of AML, VAL and HCT were prepared within their corresponding concentration ranges. The absorption spectra of the prepared mixtures were recorded in the range of (200-400 nm); and transferred to Matlab $^{\circledR}$ (version 7.9), with PLS toolbox 2.0, for subsequent data manipulation.

\section{Application to laboratory prepared mixtures (validation set for PLS)}

Into a series of $10 \mathrm{ml}$ volumetric flask, accurate aliquots of AML, VAL and HCT were transferred from their working solutions to prepare seven mixtures containing different ratios of the cited drugs. The volumes were completed with the solvent mixture. The spectra of the prepared solutions were recorded at $(200-400 \mathrm{~nm})$. The concentration of each drug was calculated by substitution in the corresponding regression after applying the corresponding manipulating steps for each method.

\section{Application to pharmaceutical formulations}

Five tablets of each exforge HCT ${ }^{\circ}$ formulations were accurately weighed and finely powdered. An amount of the powder equivalent to $6.4 \mathrm{mg}$ VAL was weighed and dissolved in the solvent mixture by shaking in an ultrasonic bath for about $30 \mathrm{~min}$. The working solutions were filtered into separate $100 \mathrm{ml}$ measuring flasks, and the volume was completed with a solvent mixture. For each formulation, five $\mathrm{ml}$ was transferred from its working solution into $10 \mathrm{ml}$ measuring flasks. Then formulation (A) was spiked with $60 \mu \mathrm{g}$ of AML, while formulation (B) was spiked with $40 \mu \mathrm{g}$ of AML from its working solution and completed to volume with a solvent mixture. The spectra of these solutions were scanned from 200 to $400 \mathrm{~nm}$ and stored in the computer. The same procedure under AAC was applied and the concentrations of AML, VAL, and HCT were calculated from the corresponding regression equations. The claimed concentration of AML in both formulations was calculated after subtraction of the added concentration (standard solution of AML $4 \mu \mathrm{g} / \mathrm{ml}$ analyzed by using the same procedure). When carrying out the standard addition technique, different known concentrations of the pure standard of each drug were added to the pharmaceutical formulations before proceeding in the previously mentioned methods.

\section{RESULTS AND DISCUSSION}

Exforge HCT $®$ is present in the market as two formulations with different ratios of the drugs AML, VAL and HCT. Formulation (A) with ratio $10 / 160 / 25$ of AML/VAL/HCT while formulation (B) with ratio $5 / 160 / 12.5$ of $\mathrm{AML} / \mathrm{VAL} / \mathrm{HCT}$, respectively. Advanced amplitude centering (AAC) was applied for the determination of this ternary mixture using centered amplitudes at a single wavelength. In the first formulation, higher concentrations of AML is present which suggested the approach of the partially overlapping spectrum; while the second one, lower concentrations of AML is present which suggested the approach of the completely overlapping spectrum. The results of both approaches of AAC were compared to PLS model. 
The overlapping zero-order absorption spectra $\left(D_{0}\right)$ of AML, VAL and HCT is shown in fig. 1.

\section{Advanced amplitude centering (AAC) via partially overlapped spectra approach}

This novel approach was applied to resolve the components of the ternary mixture progressively using single divisor, the spectrum of AML is extended than both VAL and HCT and eliminate the extended spectrum of AML the resolved binary mixture of VAL and HCT exhibit complete overlapped ratio spectra at two wavelengths $\lambda_{1}$ and $\lambda_{2}$ where amplitude difference of HCT aren't equal zero between those two wavelengths $\lambda_{1}$ and $\lambda_{2}$., so the well-established constant center method [30] cannot be applied.

The spectra of the laboratory prepared mixture of the three components were divided by $24 \mu \mathrm{g} / \mathrm{ml} \mathrm{AML'}$ as a divisor to obtain the ratio spectra $(\mathrm{VAL} / \mathrm{AML})+(\mathrm{HCT} / \mathrm{AML})+(\mathrm{AML} / \mathrm{AML})$, fig. 2, where (AML/AML') represented a constant that can be measured accurately at the plateau region in the range of (350$380 \mathrm{~nm}$ ) at concentrations higher than or equal to $6 \mu \mathrm{g} / \mathrm{ml}$ of AML.

The constant amplitude was measured at the plateau region and substituted in the corresponding regression equation to calculate the concentration of AML. By subtracting this constant, we obtain the ratio spectra of the binary mixture of VAL and HCT.

The concentration of HCT was determined using amplitude difference at $\lambda_{1}$ and $\lambda_{2}$, where $\lambda_{1}$ equals to $275.5 \mathrm{~nm}$ which exhibits maximum amplitude for HCT ratio spectrum. The amplitude of the interfering substance (VAL) between those two selected wavelengths at $\lambda_{1}$ and $\lambda_{2}$ (275.5 and $239.5 \mathrm{~nm}$ ) weren't equal (amplitude difference does not equal zero), so the conventional constant centre method could not be applied. To cancel the effect of VAL, its equality factor (F) was calculated at the two selected wavelengths $\left(\mathrm{P}_{275.5} / \mathrm{P}_{239.5}\right)$.

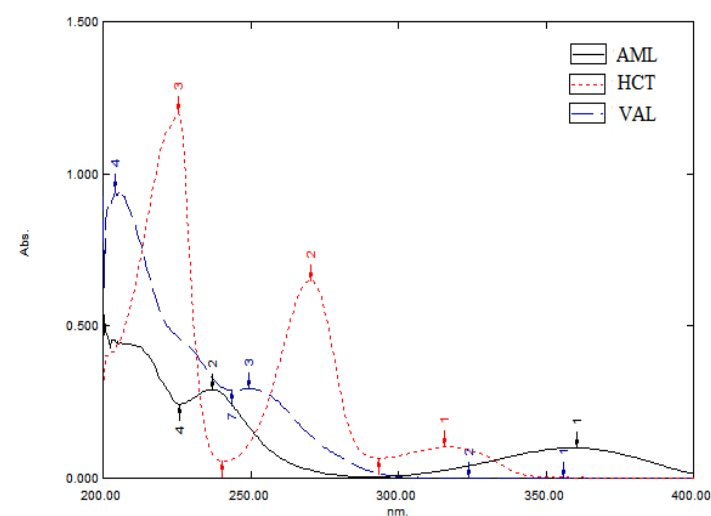

Fig. 1: UV spectra of $10 \mu \mathrm{g} / \mathrm{ml}$ of each of ML, VAL and HCT in in a solvent mixture of methanol: water $(50: 50 \mathrm{v} / \mathrm{v})$

The amplitude difference $(\Delta \mathrm{P})$ at $(275.5239 .5 \mathrm{~nm})$ of the ratio spectra of HCT was calculated after multiplying the later by F. The postulated amplitude value (HCT/AML') [P postulated] at $275.5 \mathrm{~nm}$ can be calculated by substitution in the equation representing the linear relationship between the differences of ratio amplitude $(\Delta \mathrm{P}$ 275.5-239.5) versus the corresponding ratio amplitudes at $275.5 \mathrm{~nm}$.

$$
\Delta \mathrm{P}=0.9613\left(\mathrm{HCT} / \mathrm{AML}^{\prime}\right)+0.0141(\mathrm{r}=0.9994)
$$

The amplitude of VAL at the same point $(275.5 \mathrm{~nm})$ could be measured by calculating the difference between the recorded amplitude of the mixture $[\mathrm{P}$ recorded $]$ and postulated amplitude of HCT [P postulated $]$ at the same point $275.5 \mathrm{~nm}$ via amplitude difference method.

The concentrations of each of VAL and HCT were calculated using its corresponding regression equation representing the linear relationship between their amplitude values of ratio spectra at 275.5 $\mathrm{nm}$ versus their corresponding concentration.

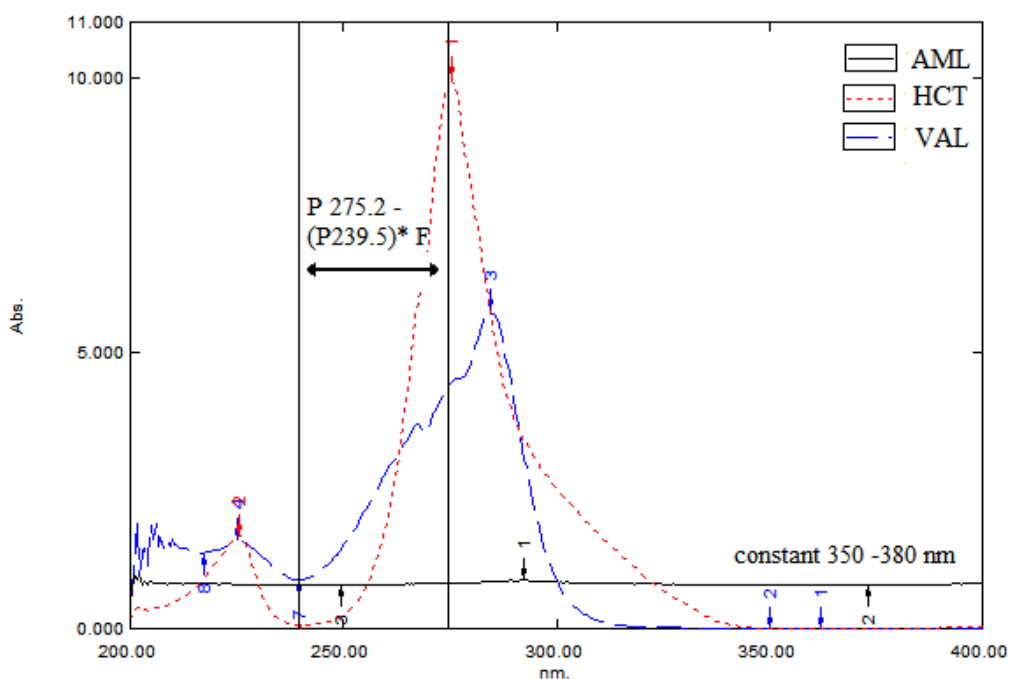

Fig. 2: Ratio spectra of $20 \mu \mathrm{g} / \mathrm{ml}$ of each of AML, HCT and VAL using AML' divisor ( $24 \mu \mathrm{g} / \mathrm{ml}$ )

\section{Advanced Amplitude centering (AAC) via completely overlapped spectra approach}

This approach would be applied in the case of severely overlapped spectra of the three components in a mixture using single divisor. It starts with dividing the spectrum of the laboratory prepared mixture by $24 \mu \mathrm{g} / \mathrm{ml}$ AML' as a divisor to obtain the ratio spectra (VAL/AML')+(HCT/AML')+(AML/AML'), fig. 3. At concentrations lower than $6 \mu \mathrm{g} / \mathrm{ml}$ of AML, the constant amplitude of (AML/AML') cannot be measured accurately at the plateau region in the range of
(350-380 nm) due to high noise to signal ratio. So the three components would be progressively determined using the centred amplitude at a single wavelength.

The concentration of HCT was determined using amplitude difference at $\lambda_{1}$ and $\lambda_{2},(275.5$ and $289.5 \mathrm{~nm})$, where the amplitude difference for the interfering substance (VAL) and the amplitude difference for AML constant between those two selected wavelengths would be equal to zero; so the amplitude difference would only be related to HCT. The postulated amplitude value 
(HCT/AML') [P postulated] at $289.5 \mathrm{~nm}$ could be calculated by substitution in the equation representing the linear relationship between the difference of ratio amplitude $(\Delta \mathrm{P})$ at $(275.5-289.5$ $\mathrm{nm}$ ) versus the corresponding ratio amplitudes at $289.5 \mathrm{~nm}$.

$$
\Delta \mathrm{P}=2.2504\left(\mathrm{HCT} / \mathrm{AML}^{\prime}\right)-2.2861(\mathrm{r}=0.9992)
$$

The concentration of VAL was determined using amplitude difference at $\lambda_{1}$ and $\lambda_{2}$, (289.5 and $264.5 \mathrm{~nm}$ ), where the amplitude difference for the interfering substance (HCT) and the amplitude difference for AML constant between those two selected wavelengths would be equal to zero; so the amplitude difference would only be related to VAL. The postulated amplitude value (VAL/AML') [P postulated] at $289.5 \mathrm{~nm}$ could be calculated by substitution in the equation representing the linear relationship between the differences of ratio amplitude $(\Delta \mathrm{P})$ at $(289.5-264.5 \mathrm{~nm})$ versus the corresponding ratio amplitudes at $289.5 \mathrm{~nm}$.

$$
\Delta \mathrm{P}=0.3205\left(\mathrm{VAL} / \mathrm{AML}^{\prime}\right)-0.3288(\mathrm{r}=0.9993)
$$

The constant amplitude of AML at the same point (289.5 nm) could be measured by calculating the difference between the recorded amplitude of the mixture [P recorded] and postulated amplitudes of both HCT and VAL [P postulated] at the same point $289.5 \mathrm{~nm}$ via amplitude difference method.

The concentrations of each of AML, VAL and HCT were calculated using its corresponding regression equation representing the linear relationship between their amplitude values of ratio spectra at 289.5 $n m$ versus their corresponding concentration.

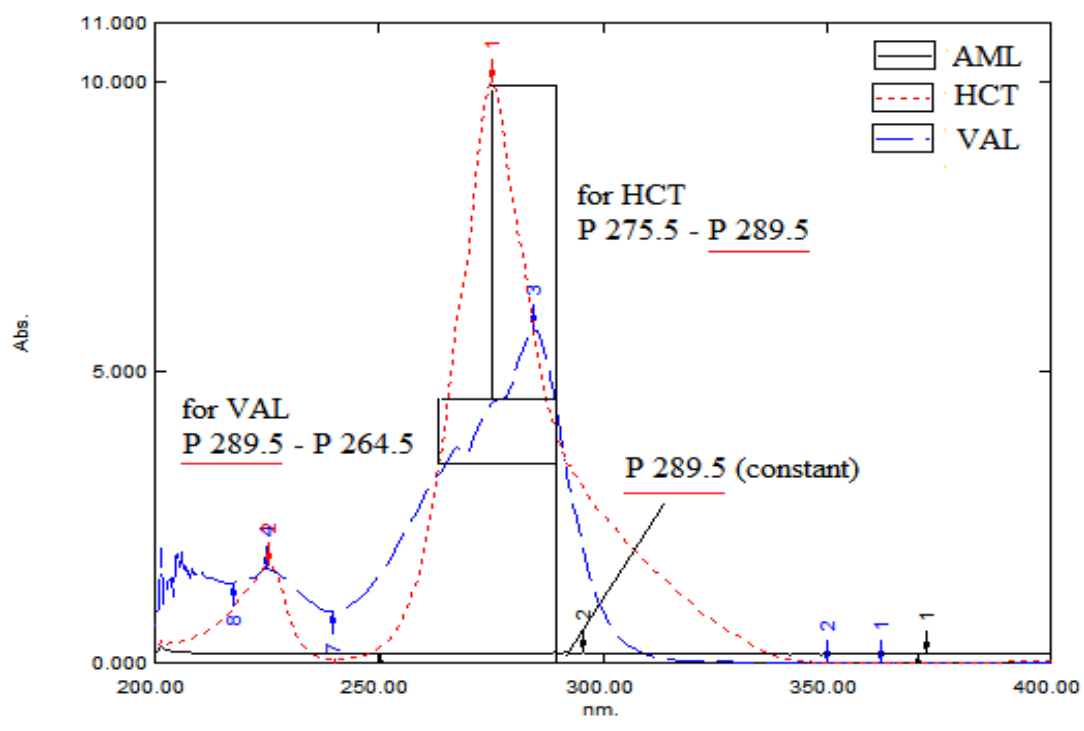

Fig. 3: Ratio spectra of $4 \mu \mathrm{g} / \mathrm{ml}$ of AML and $20 \mu \mathrm{g} / \mathrm{ml}$ of each of HCT and VAL using AML' divisor (24 $\mu \mathrm{g} / \mathrm{ml})$

The selected divisor for both approaches was chosen to compromise between minimal noise and maximum sensitivity and gave the best results regarding average recovery percent when used for the analysis the laboratory prepared mixtures. The validation parameters for the proposed approaches were listed in table 1.

This technique was introduced as a novel progressive technique for resolving complex mixtures where two components were completely overlapped, but they were more extended than the third one (first approach) or with severely overlapped spectra of the three components (second approach).

The advantage of this novel technique over the other manipulating ratio spectra methods applied for ternary mixtures (as successive derivative ratio and mean centering of ratio spectra) was requiring one divisor only and utilizing the centered amplitude at single wavelength for the progressive resolution and determination of the three components, so it saved time and avoided several manipulations.

\begin{tabular}{|c|c|c|c|c|c|c|}
\hline \multirow[t]{2}{*}{ Parameters } & \multicolumn{3}{|c|}{ AAC via partially overlapped spectra approach } & \multicolumn{3}{|c|}{ AAC via severely overlapped spectra approach } \\
\hline & AML & VAL & HCT & AML & VAL & HCT \\
\hline Wavelength $(\mathrm{nm})$ & $350-380$ & 275.5 & & 289.5 & & \\
\hline $\begin{array}{l}\text { Calibration range a } \\
\mu \mathrm{g} / \mathrm{ml}\end{array}$ & $6-32$ & $2-36$ & $2-20$ & $4-32$ & $6-36$ & $2-20$ \\
\hline Slope & 0.0431 & 0.1711 & 1.1533 & 0.4360 & 0.1875 & 0.3556 \\
\hline Intercept & -0.0093 & 0.0246 & -0.0946 & -0.0238 & -0.0192 & 0.0409 \\
\hline Correlation coefficient (r) & 0.9994 & 0.9997 & 0.9999 & 0.9997 & 0.9991 & 0.9998 \\
\hline Mean a & 100.16 & 99.81 & 100.22 & 100.32 & 99.95 & 99.88 \\
\hline RSD \% & 1.381 & 1.224 & 0.906 & 1.060 & 1.248 & 0.946 \\
\hline \multirow[t]{2}{*}{ Accuracy ab } & 100.51 & 100.75 & 99.11 & 99.99 & 99.68 & 100.21 \\
\hline & \pm 0.87 & \pm 0.65 & \pm 0.74 & \pm 0.75 & \pm 1.05 & \pm 0.85 \\
\hline Repeatability ac & 0.621 & 1.002 & 0.623 & 0.788 & 0.911 & 0.778 \\
\hline Inter-day precision ac & 0.744 & 1.133 & 0.775 & 0.817 & 0.963 & 0.798 \\
\hline Robustness acd & 0.411 & 0.963 & 0.825 & 1.003 & 0.755 & 0.933 \\
\hline
\end{tabular}

Table 1: Assay parameters and validation sheet obtained by applying the proposed AAC approaches

aAverage of three experimen 12 , bmean \pm standard deviation of 3 concentrations of each drug $(8,10$ and $12 \mu \mathrm{g} / \mathrm{ml})$, $\mathrm{c}$ Relative standard deviation of 3 concentrations of each drug $(8,10$ and $12 \mu \mathrm{g} / \mathrm{ml})$, dRobustness were checked by testing the effect of solvent $(45,55,60 \%$ methanol). 


\section{PLS mode}

The calibration set was constructed using the absorption spectra set of 15 mixtures, as listed in table 2 . The initial model was found to give bad results so the regions above $350 \mathrm{~nm}$ were rejected. Cross-validation methods leaving out one sample at a time was employed. The root means squares error of cross-validation (RMSECV) was calculated which was used as a diagnostic test for examining the errors in the predicted concentrations. It indicated both precision and accuracy of predictions. The selected model was that with the smallest number of factors such that RMSECV for that model was not significantly greater than RMSECV from the model with an additional factor. A number of factors of 4 were found to be optimum for the mixture, as shown in Fig.4. To assess the prediction ability of the suggested models, an external validation set was used.

The predicted concentrations were compared with the true concentrations of the compounds in each sample. The root mean squared errors of prediction (RMSEP) and the regression equations for the predicted versus actual concentration, were listed in table 3 as diagnostic tools for model validation.

The selectivity of the proposed procedures was assessed by the analysis of laboratory prepared mixtures (validation set for PLS) containing different ratios of the cited drugs, where satisfactory results were obtained as shown in table 4 .

Table 2: Concentrations of AML, VAL and HCT in the calibration set (PLS model)

\begin{tabular}{|c|c|c|c|c|c|c|}
\hline \multirow[t]{2}{*}{ Experiment no. } & \multicolumn{3}{|l|}{ Levels } & \multicolumn{3}{|c|}{ Conc $(\mu \mathrm{g} / \mathrm{ml})$} \\
\hline & AML & VAL & HCT & AML & VAL & HCT \\
\hline 1 & 0 & 0 & 0 & 20 & 22 & 10 \\
\hline 2 & -2 & 2 & -1 & 4 & 2 & 6 \\
\hline 3 & 2 & -1 & 2 & 36 & 42 & 18 \\
\hline 4 & 2 & 0 & -1 & 36 & 42 & 6 \\
\hline 5 & 0 & -1 & -1 & 20 & 22 & 6 \\
\hline 6 & -1 & 1 & 2 & 12 & 12 & 18 \\
\hline 7 & 1 & 2 & 1 & 28 & 32 & 14 \\
\hline 8 & 1 & 0 & 2 & 28 & 32 & 18 \\
\hline 9 & 0 & 2 & 2 & 20 & 22 & 18 \\
\hline 10 & 2 & -2 & 1 & 36 & 42 & 14 \\
\hline 11 & -2 & 1 & -2 & 4 & 2 & 2 \\
\hline 12 & -2 & 0 & 1 & 4 & 32 & 14 \\
\hline 13 & 0 & 1 & 1 & 20 & 32 & 14 \\
\hline 14 & 1 & -1 & -2 & 28 & 2 & 2 \\
\hline 15 & -2 & -1 & 0 & 4 & 22 & 10 \\
\hline
\end{tabular}

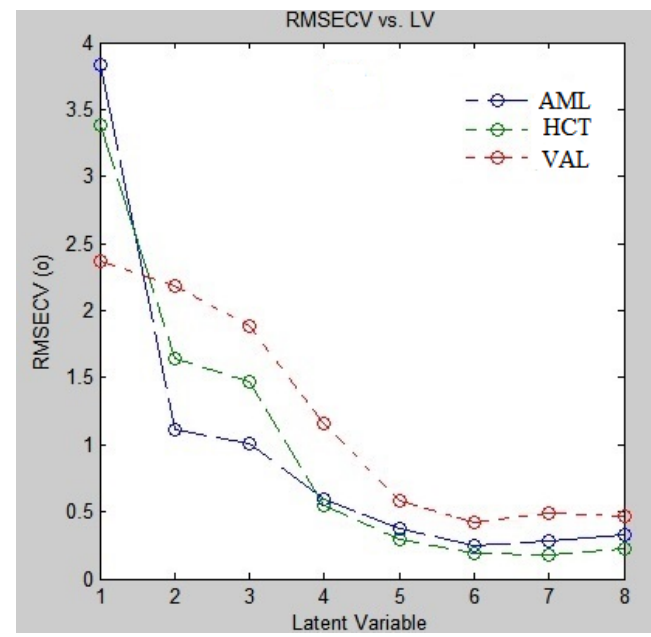

Fig. 5: RMSECV of the calibration set of AML, HCT and VAL as a function of latent variables

\section{Application for pharmaceutical formulations}

Formulation (A) with ratio 10/160/25 of AML/VAL/HCT, where concentrations of AML is higher than or equal $6 \mu \mathrm{g} / \mathrm{ml}$, was analyzed using the approach of partial overlapping spectrum of Advanced amplitude centering (AAC); while formulation (B) with ratio $5 / 160 / 12.5$ of AML/VAL/HCT, where concentrations of AML is lower than $6 \mu \mathrm{g} / \mathrm{ml}$, was analyzed using the approach of sever overlapping spectrum of Advanced amplitude centering (AAC). Both formulations were analyzed using PLS model and the results were compared to AAC approaches where no difference was observed. The validity of the proposed approaches was further assessed by applying the standard addition technique showing no excipients' interference. The results obtained were shown in table 5 .

Table 3: Summary of results obtained by applying the diagnostic tools for model validation of the PLS model

\begin{tabular}{|c|c|c|c|}
\hline Parameters & AML & VAL & HCT \\
\hline Slope & 1.0521 & 0.9996 & 0.9705 \\
\hline Intercept & -0.2828 & 0.0657 & 0.1029 \\
\hline Correlation coefficient $(r)$ & 0.9997 & 0.9990 & 0.9991 \\
\hline RMSEP & 0.343 & 0.102 & 0.053 \\
\hline
\end{tabular}


Table 4: Analysis of laboratory prepared mixtures by applying the proposed spectrophotometric methods

\begin{tabular}{|c|c|c|c|c|c|c|c|c|c|}
\hline \multirow[t]{3}{*}{$\begin{array}{l}\text { AML: VAL: HCT } \\
\text { in }(\mu \mathrm{g} / \mathrm{ml})\end{array}$} & \multicolumn{3}{|c|}{$\begin{array}{l}\text { AAC } \\
\text { via partially overlapped spectra approach }\end{array}$} & \multicolumn{3}{|c|}{$\begin{array}{l}\text { AAC } \\
\text { via severely overlapped spectra approach }\end{array}$} & \multicolumn{3}{|l|}{ PLS } \\
\hline & AML & VAL & HCT & AML & VAL & HCT & AML & VAL & HCT \\
\hline & \multicolumn{9}{|c|}{ Recovery \%a } \\
\hline 10: $10: 10$ & 101.71 & 99.88 & 100.11 & 101.36 & 99.56 & 100.95 & 101.22 & 99.66 & 100.15 \\
\hline 20: $10: 10$ & 99.96 & 99.25 & 100.67 & 99.36 & 99.34 & 101.06 & 99.64 & 98.96 & 100.35 \\
\hline $6: 6: 18$ & 99.63 & 100.67 & 100.34 & 99.46 & 101.07 & 99.66 & 99.39 & 101.22 & 99.55 \\
\hline 10: $30: 10$ & 99.38 & 99.38 & 99.87 & 99.35 & 99.36 & 98.79 & 99.57 & 100.58 & 100.79 \\
\hline $12: 4: 4$ & 100.98 & 99.88 & 99.54 & 98.85 & 99.87 & 99.63 & 99.32 & 100.89 & 100.44 \\
\hline $8: 32: 5^{b}$ & 100.64 & 100.64 & 98.86 & 100.95 & 101.22 & 99.21 & 101.08 & 99.36 & 100.27 \\
\hline $5: 32: 2.5^{c}$ & 96.21 & 99.47 & 99.05 & 101.02 & 99.37 & 100.58 & 100.38 & 98.88 & 101.08 \\
\hline Mean & 99.79 & 99.88 & 99.78 & 100.05 & 99.97 & 99.98 & 100.09 & 99.94 & 100.38 \\
\hline \pm SD & 1.77 & 0.58 & 0.67 & 1.02 & 0.82 & 0.89 & 0.81 & 0.95 & 0.49 \\
\hline
\end{tabular}

${ }^{a}$ Average of 3 experiments, bratio present in exforge $₫$ formulation (A), rratio present in exforge $₫$ formulation (B)

Table 5: Application of standard addition technique to the analysis of exforge $®$ formulations by applying the proposed methods

\begin{tabular}{|c|c|c|c|c|}
\hline Methods & $\begin{array}{l}\text { AAC via partially overlapped } \\
\text { spectra approach }\end{array}$ & $\begin{array}{l}\text { AAC via severely overlapped spectra } \\
\text { approach }\end{array}$ & PLS & PLS \\
\hline Exforge $\AA$ & Formulation $(\mathrm{A})^{\mathrm{a}}$ & Formulation $(\mathrm{B})^{\mathrm{a}}$ & Formulation $(\mathrm{A})^{\mathrm{a}}$ & Formulation (B) \\
\hline AML & $100.25 \pm 0.69$ & $98.36 \pm 0.61$ & $100.61 \pm 0.04$ & $99.15 \pm 0.82$ \\
\hline Standard addition & $99.64 \pm 0.54$ & $99.11 \pm 0.44$ & $99.71 \pm 0.99$ & $99.05 \pm 0.49$ \\
\hline VAL & $101.52 \pm 0.87$ & $100.87 \pm 0.62$ & $101.88 \pm 0.71$ & $99.52 \pm 0.73$ \\
\hline Standard addition ${ }^{\mathrm{b}}$ & $99.99 \pm 0.78$ & $100.67 \pm 0.82$ & $100.87 \pm 0.76$ & $100.96 \pm 0.34$ \\
\hline HCT & $102.00 \pm 0.89$ & $99.15 \pm 0.32$ & $101.54 \pm 0.79$ & $99.52 \pm 0.41$ \\
\hline Standard addition ${ }^{\mathrm{b}}$ & $99.73 \pm 0.96$ & $101.08 \pm 0.44$ & $99.88 \pm 0.39$ & $101.45 \pm 0.63$ \\
\hline
\end{tabular}

${ }^{a}$ mean $\pm S D$ for six experiments, ${ }^{~}$ Average of three experiments (pure added equivalent to 8, 10,12 $\mu \mathrm{g} / \mathrm{ml}$ of AML, and 6, 7, $8 \mu \mathrm{g} / \mathrm{ml}$ of VAL and HCT)

Table 6: Statistical comparison between the results obtained by the proposed methods and the reported methods for the determination of AML, VAL and HCT in pure powder form

\begin{tabular}{|c|c|c|c|c|c|c|c|c|c|c|c|c|}
\hline \multirow[t]{2}{*}{ Items } & \multicolumn{4}{|l|}{ AML } & \multicolumn{4}{|l|}{ VAL } & \multicolumn{4}{|l|}{ HCT } \\
\hline & $\begin{array}{l}\text { AAC } \\
\text { (partial) }\end{array}$ & $\begin{array}{l}\text { AAC } \\
\text { (Severe) }\end{array}$ & PLS & $\begin{array}{l}\text { Reported } \\
\text { methoda }^{\text {[9] }} \\
\text { [] }\end{array}$ & $\begin{array}{l}\text { AAC } \\
\text { (partial) }\end{array}$ & $\begin{array}{l}\text { AAC } \\
\text { (Severe) }\end{array}$ & PLS & $\begin{array}{l}\text { Reported } \\
\text { methoda } \\
{[12]}\end{array}$ & $\begin{array}{l}\text { AAC } \\
\text { (partial) }\end{array}$ & $\begin{array}{l}\text { AAC } \\
\text { (Severe) }\end{array}$ & PLS & $\begin{array}{l}\text { Reported } \\
\text { methoda } \\
\text { [14] }\end{array}$ \\
\hline Mean $\%$ & 100.16 & 100.32 & 100.09 & 100.31 & 99.81 & 99.95 & 99.94 & 100.30 & 100.22 & 99.88 & 100.38 & 100.32 \\
\hline Variance & 1.9057 & 1.1216 & 0.6495 & 0.3913 & 1.4802 & 1.5578 & 0.9082 & 1.5274 & 0.8201 & 0.8943 & 0.2361 & 0.7472 \\
\hline $\mathrm{n}$ & 7 & 7 & 7 & 5 & 7 & 7 & 7 & 5 & 7 & 7 & 7 & 5 \\
\hline $\begin{array}{l}\text { Student's } \\
t \text {-test }{ }^{\mathrm{b}}\end{array}$ & 0.224 & 0.010 & 0.523 & & 0.691 & 0.472 & 0.581 & & 0.186 & 0.764 & 0.153 & \\
\hline$F$ value cd & $4.870^{c}$ & $2.866^{c}$ & $1.660^{\mathrm{c}}$ & & $1.032^{d}$ & $1.020^{c}$ & $\begin{array}{l}1.682 \\
d\end{array}$ & & $1.098^{c}$ & $1.197^{c}$ & $\begin{array}{l}3.165 \\
d\end{array}$ & \\
\hline
\end{tabular}

aReported methods for AML and VAL are chromatographic methods, while for HCT, it is a chemometric method, bthe corresponding tabulated values of $t$ equals to 2.228 at $\mathrm{P}=0.05$, cthe corresponding tabulated values of $F$ equals to 6.094 at $\mathrm{P}=0.05$, d the corresponding tabulated values of $F$ equals to 4.120 at $\mathrm{P}=0.05$

The proposed spectrophotometric methods were validated in compliance with the ICH guidelines [35] as shown in table 1. The data showed that the methods were accurate, precise, robust and specific over the specified range. Statistical comparison of the results obtained by the proposed methods and reported ones was shown in table 6. The calculated $\mathrm{t}$ and $\mathrm{F}$ values were less than the theoretical ones indicating that there was no significant difference between the proposed and the reported methods with respect to accuracy and precision.

\section{CONCLUSION}

This work introduced the novel approaches of advanced amplitude centering (AAC) which could be applied for solving overlapped spectra of the components in ternary mixtures either partially or severely overlapped. The advantage of the novel advanced amplitude centering approaches was the determination of three components in their ternary mixture with minimum absorbance data manipulation by unified wavelength resolution using single divisor. The resolution efficiency of the results were compared with those obtained by chemometric method PLS, where satisfactory results were obtained. The proposed method AAC was simpler than other reported spectrophotometric methods as it did not require sample preparation, buffer preparation, expensive solvents or sophisticated liquid chromatographic instruments. As a final conclusion, the proposed univariate method was superior over other reported univariate methods since it had very high-resolution power when applied to ternary mixtures with partially or severely overlapped spectra without any limitations and with good accuracy and precision; therefore it could be considered as an alternative to chemometric methods with minimum sample preparation so they could be easily applied in quality control laboratories for the simultaneous determination of amlodipine (AML), valsartan (VAL) and hydrochlorothiazide (HCT).

\section{CONTRIBUTION OF AUTHORS}

Both authors had equal contributions in the presented work.

\section{CONFLICT OF INTERESTS}

Authors declared no conflict of interests.

\section{REFERENCES}

1. Mahadkar S, Valvi S, Jadhav V. Gas chromatography-mass spectroscopic (GCMS) analysis of some bioactive compounds form five medicinally relevant wild edible plants. Asian J Pharm Clin Res 2013;6:136-9. 
2. Burhan A, Vyas B. A rapid, sensitive and validated ultraperformance liquid chromatography and tandem mass spectrometry method for determination of rifampicin in rat plasma: application to pharmacokinetic study. Int J Pharm Pharm Sci 2017;9:222-7.

3. Salem H, Lotfy HM, Hassan NY, El-Zeiny MB, Saleh SS. A comparative study of different aspects of manipulating ratio spectra applied for ternary mixtures: derivative spectrophotometry versus wavelet transform. Spectrochim Acta Part A 2015;135:1002-10.

4. Lotfy HM, Saleh SS, Hassan NY, Salem H. A comparative study of novel spectrophotometric methods based on isosbestic points; application on a pharmaceutical ternary mixture. Spectrochim Acta Part A 2014;126:112-21.

5. Lotfy HM, Tawakkol SM, Fahmy NM, Shehata MA. Validated stability indicating spectrophotometric methods for the determination of lidocaine hydrochloride, calcium dobesilate, and dexamethasone acetate in their dosage forms. Anal Chem Lett 2013;3:208-25.

6. Moustafa AA, Salem H, Hegazy M, Ali O. Evaluating the efficiency of spectral resolution of univariate methods manipulating ratio spectra and comparing to multivariate methods: an application to the ternary mixture in common cold preparation. Spectrochim Acta Part A 2015;137:1363-73.

7. Darwish HW. Application of smart spectrophotometric methods and artificial neural network for the simultaneous quantitation of olmesartan medoxamil, amlodipine besylate and hydrochlorothiazide in their combined pharmaceutical dosage form. Chem Cent J 2013;7:22-31.

8. Darwish HW, Hassan SA, Salem MY, El-Zeany BA. Three different methods for determination of a binary mixture of amlodipine and atorvastatin using dual wavelength spectrophotometry. Spectrochim Acta Part A 2013;104:70-6.

9. Darwish HW, Backeit AH. Multivariate versus classical univariate calibration methods for spectrofluorimetric data: application to the simultaneous determination of olmesartan medoxamil and amlodipine besylate in their combined dosage form. J Fluoresc 2013;23:79-91.

10. Zaazaa HE, Abbas SS, Essam HM, El-Bardicy MG. Validated chromatographic methods for determination of perindopril and amlodipine in the pharmaceutical formulation in the presence of their degradation products. J Chromatogr Sci 2013; 51:533-43.

11. Li J, Li Y, Zhang W, Chen Z, Fan G. Glucose- $\beta$-CD interaction assisted ACN field-amplified sample stacking in CZE for determination of trace amlodipine in beagle dog plasma. J Sep Sci 2013;36:1817-25.

12. Bharati AR, Deshmane SV, Biyani KR. Stability indicating RPHPLC method development and validation for simultaneous estimation of amlodipine and hydrochlorothiazide in pharmaceutical dosage form. Int J Chem Pharm Res 2014;6:16-9.

13. Mallegowda SM, Deepakumari HN, Revanasiddappa HD. Spectrophotometric determination of valsartan using $p$ chloranilic acid as $\pi$-acceptor in pure and in dosage forms. J Appl Pharm Sci 2013;3:113-6.

14. Imam SS, Ahad A, Aqil M, Sultana Y, Ali A. A validated RP-HPLC method for simultaneous determination of propranolol and valsartan in bulk drug and gel formulation. J Pharm Bioallied Sci 2013;5:61-6.

15. Li Z, Chen F, Wang X, Wang C. Ionic liquids dispersive liquidliquid microextraction and high-performance liquid chromatographic determination of irbesartan and valsartan in human urine. Biomed Chromatogr 2013;27:254-8.

16. Brahmaiah B, Sujana K, Prameela Rani A. Development and validation of a RP-HPLC method for simultaneous determination of ramipril and valsartan in bulk and pharmaceutical dosage forms. Asian J Pharm Clin Res 2013;6:23-5.

17. Ferreira MH, Braga JWB, Sena MM. Development and validation of a chemometric method for direct determination of hydrochlorothiazide in pharmaceutical samples by diffuse reflectance near infrared spectroscopy. Microchem J 2013; 109: 158-64.

18. Qiu X, Wang Z, Wang B, Zhan H, Pan X, Xu R-a. Simultaneous determination of irbesartan and hydrochlorothiazide in human plasma by ultra-high performance liquid chromatography- tandem mass spectrometry and its application to a bioequivalence study. J Chromatogr B 2014;957:110-5.

19. Hammouda MEA, Abu El-Enin MA, El-Sherbiny DT, El-Wasseef DR, El-Ashry SM. Simultaneous determination of enalapril and hydrochlorothiazide in pharmaceutical preparations using microemulsion liquid chromatography. J Chromatogr Sci 2015;53:90-6.

20. Abdallah OM, Badawey AM. Determination of amlodipine and valsartan in the binary mixture using derivative-ratio spectrophotometric, chemometric and high-performance liquid chromatographic-UV methods. Int J Ind Chem 2011;2:131-9.

21. Al-Shaalan NH, Alnowaiser MA. Simultaneous determination of Amlodpine besylate and Valsartan in the pharmaceutical formulation using high-performance liquid chromatography. J Chem Pharm Res 2010;2:129-34.

22. Merey HA, Ramadan NK, Diab SS, Moustafa AA. Spectrophotometric methods for simultaneous determination of a ternary mixture of amlodipine besylate, olmesartan medoxomil and hydrochlorothiazide. Spectrochim Acta Part A 2014;125:138-46.

23. Salim MM, Ebeid WM, El-Enany N, Belal F, Walash MI, Patonay G. Simultaneous determination of aliskiren hemifumarate, amlodipine besylate, and hydrochlorothiazide in their triple mixture dosage form by capillary zone electrophoresis. J Sep Sci 2014;37:1206-13.

24. Rezk MR, El-Remali NM, Abdel-Aleem AE. Simultaneous determination of valsartan and hydrochlorothiazide in their pharmaceutical formulations. Pharm Chem 2012;4:529-37.

25. Lotfy HM, Hegazy MA, Mowaka S, Mohamed EH. Novel spectrophotometric methods for simultaneous determination of amlodipine, valsartan and hydrochlorothiazide in their ternary mixture. Spectrochim Acta Part A 2015;140:495-508.

26. Darwish HW, Hassan SA, Salem MY, El-Zeany BA. Sequential spectrophotometric method for the simultaneous determination of amlodipine, valsartan, and hydrochlorothiazide in coformulated tablets. Int J Spectrosc 2013;2:1-8.

27. Darwish HW, Hassan SA, Salem MY, El-Zeany BA. Comparative study between derivative spectrophotometry and multivariate calibration as analytical tools applied for the simultaneous quantitation of amlodipine, valsartan and hydrochlorothiazide. Spectrochim Acta Part A 2013;113:215-23.

28. Darwish HW, Hassan SA, Salem MY, El-Zeany BA. Different approaches in partial least squares and artificial neural network models applied for the analysis of a ternary mixture of amlodipine, valsartan and hydrochlorothiazide. Spectrochim Acta Part A 2014;122:744-50.

29. Darwish HW, Hassan SA, Salem MY, El-Zeany BA. Rapid and sensitive TLC and HPLC with on-line wavelength switching methods for simultaneous quantitation of amlodipine, valsartan and hydrochlorothiazide in pharmaceutical dosage forms. Int J Pharm Biol Sci 2013;4:345-6.

30. Saleh SS, Lotfy HM, Hassan NY, Salem H. A comparative study of progressive versus successive spectrophotometric resolution techniques applied for pharmaceutical ternary mixtures. Spectrochim Acta Part A 2014;132:239-48.

31. Lotfy HM. Determination of simvastatin and ezatimibe in combined tablet dosage forms by the constant center spectrphoto-metric method. Int J Pharm Pharm Sci 2012;4:673-9.

32. British Pharmacopoeia. Volume II. London; 2009.

33. Brereton RG. Chemometrics: data analysis for the laboratory and chemical plant. USA: John Wiley and Sons, Ltd; 2003.

34. Ebrahimi-Najafabadi H, Leardi R, Jalali-Heravi Mi. Experimental design in analytical chemistry part I: theory. J AOAC Int 2014;97:3-11.

35. International Conference on Harmonization (ICH) QB. Validation of Analytical Procedures: Methodology. Federal Register; 1997. p. 62.

\section{How to cite this article}

- Hayam M Lotfy, Sarah S Saleh. Advanced amplitude centering as an invigorating manipulation for unified wavelength spectral resolution of ternary mixtures. Int J Pharm Pharm Sci 2017;9(5):43-50. 